\title{
A realist approach to science and practice in psychology
}

\author{
David J.F. Maree \\ Department of Psychology, Faculty of Humanities, University of Pretoria, South Africa
}

\section{Corresponding author:}

David JF Maree, Department of Psychology, Faculty of Humanities, University of Pretoria, Private Bag X20, Hatfield, Pretoria 0028, South Africa.

Email: David.Maree@up.ac.za

\begin{abstract}
The possibility of uniting science and practice in psychology is considered. The main aim is to explore the ability of a realist approach to address the various dichotomies prevalent in psychology. The multileveled demands of the society, government, and tertiary training are briefly discussed. The multitude of mental health needs in South African society is addressed by government with a number of policies and legislative processes. In addition, training of psychologists is under pressure because of the changing demands within higher education institutions. The pressure to function as research institutions necessitates a revisioning of the scientist-practitioner model. This model perpetuates bipolarity because of a scientistic understanding of what it means to be scientific. This article describes a realist model of science that avoids some of the more serious dichotomies so prevalent in South African psychology departments, namely, the quantitative-qualitative divide, the positivist-constructionist split, and possibly also the scientist-practitioner model. A realist image of science might achieve this integration because of the simple fact that both science and practice involve critical enquiry. Two examples of a realist psychology from neuropsychology are discussed.
\end{abstract}

\section{Keywords}

Constructionist, critical enquiry, quantitative-qualitative, realism, scientist-practitioner model

This article discusses the implications for relooking the scientist-practitioner (SP) model. First, the multileveled demands of society, government, and training are briefly discussed. It is shown that South African society is drenched in a multitude of mental health needs, which the government wants to address by a number of policies and legislative processes. Training of psychologists is under pressure because of the changing higher education landscape. The pressure to function as research institutions moves the reappraisal of the SP model to the top of the agenda. The bipolarity 
which the SP model perpetuates is possibly informed by myths about what it means to be scientific. This article thus sketches a realist model of science that avoids the pitfalls of the quantitativequalitative divide and moves beyond the positivist-constructionist dichotomy that is so popular in images of psychological science at educational institutions in South Africa. A realist image of science is able to unify even the SP polarity by emphasising a simple fact of what both science and practice involve, namely, critical enquiry. The practice of a realist psychology is illustrated with two examples from neuropsychology.

\section{The demands on professional psychology training}

In South Africa, we are well aware of particular demands placed on psychologists. Contextual demands on a number of levels play a role that determines the adequacy and relevancy of psychotherapy in a country such as South Africa and probably in the rest of Africa as well. There are governmental demands, societal demands, training demands, and, of course, the demands of practitioners themselves.

\section{Governmental demands}

With governmental demands, I am referring to the recent Ekurhuleni Declaration on Mental Health - April 2012, the Mental Health Care Act of 2002, and the National Mental Health Policy Framework and Strategic Plan 2013-2020 (Ramlall, 2012; Ramokgopa, 2012). The need is for professionals to get involved with mental health services in the country, and even the recent notice of the implementation of the certificate of need is a step in the direction of spreading resources across the country. The more formal or governmental demands which try to address societal needs by means of legislation are, of course, aimed at these societal needs which comprise mental health care across the board, mostly trying to deliver services to those who cannot afford it (Lund, Kleintjes, Kakuma, \& Flisher, 2010). As stated repeatedly, mental health needs have the second largest impact on the country's economy in terms of ill health and death, and there are multitudes suffering from depression, anxiety, and related problems (Lund, Petersen, Kleintjes, \& Bhana, 2012). Often, mental health is coupled with and exacerbated by the HIV/AIDS pandemic in the country, and we simply do not have the resources to deal with the challenges.

\section{Training demands}

Recently, a number of universities changed their focus to that of explicit research institutions. As academics know, the emphasis is very much on government subsidised activities, which means publishing in accredited journals and offering research degrees. Professional and practitionerorientated training are increasingly caught in this movement, and the pressure is on us to devise ways of emphasising research and structure degrees in such a way as to get them acknowledged as research degrees. These pressures will force us to reconsider how we present practitioner training, but the assumption for many years was that we mostly comply with the SP model of training professionals. Many training institutions internationally have faced this issue and the debate about the SP model is still strong (Chang, Lee, \& Hargreaves, 2008; Chwalisz, 2003; Clegg, 2007; Floersch, 2004; Gelso, 2006; Horn et al., 2007; Jones \& Mehr, 2007; Lilienfeld, Ritschel, Lynn, Brown, et al., 2013; Lilienfeld, Ritschel, Lynn, Cautin, \& Latzman, 2013; Lowman, 2012; Maddux \& Riso, 2007; Petocz, 2011; Rice, 1997; Sauer, 2006; Stoltenberg \& Pace, 2007; Stoltenberg et al., 2000; Tanner \& Danielson, 2007). 


\section{The SP model}

The impetus to train practitioners within the SP model originates from the initiative of a decision made at Boulder, Colorado, in 1949, and came to be known as the Boulder model (Jones \& Mehr, 2007). The SP model was built on the assumptions that research knowledge and skills play an important role in practice, that evidence for proven practices would enhance practitioner impact and research-based practice can address social issues (Jones \& Mehr, 2007). Jones and Mehr (2007) summarised the role of the practitioner as follows:

A scientist-practitioner is someone who applies critical thought to practice, uses proven treatments, evaluates treatment programs and procedures, and applies techniques and practices based on supportive literature. As such, one who embodies the role of a scientist-practitioner neatly integrates science and practice to best serve clients in a psychological realm. (p. 770)

The rise of the notion of evidence-based practice (EBP) since the early 1990s, originating in the medical environment but adopted by the social helping sciences, is another articulation of the SP model (Lilienfeld, Ritschel, Lynn, Cautin, \& Latzman, 2013). The EBP model is based on three assumptions, namely, which evidence is best and available for treatments that work, utilising clinical expertise to make decisions about treatment and the values and interest of clients influencing treatment choice (Lilienfeld, Ritschel, Lynn, Cautin, \& Latzman, 2013, pp. 885-886). EBP should be distinguished from empirically supported therapies (ESTs) which refer to only one of the assumptions of both the SP model and the EBP approach (Lilienfeld, Ritschel, Lynn, Brown, et al., 2013, p. 388).

Although training at many institutions implicitly or explicitly accepts the tenets of the SP model, the ideals of Boulder did not exactly realise as envisaged (Chang et al., 2008). A number of papers argue for a stronger emphasis on the SP model, and recently in a series of journal special issues, the matter was seriously interrogated for clinical and counselling training (Mellott, 2007; Overholser, 2007; Vespia, Sauer, \& Lyddon, 2006). The consensus is that the scientist part of the model is neglected, and recent surveys revealed interesting attitudes of practitioners towards the model (Lilienfeld, Ritschel, Lynn, Brown, et al., 2013). Like the SP model, many practitioners are reluctant to embrace even the evidence-based approach probably for similar reasons.

Some of the issues raised against adopting the EBP approach are, first, a lack of adequate emphasis on scientifically evaluated therapies at graduate level, and practitioners' entrenched beliefs in the efficacy of their own approaches. The trust in one's own intuition about the efficacy of therapies is called naïve realism. Coupled with erroneous beliefs about scientific evidence, the resistance to dropping 'tried-and-trusted' therapies in favour of unfamiliar but evidence-based ones is understandable (Lilienfeld, Ritschel, Lynn, Cautin, \& Latzman, 2013).

Second, interest and skills influence one's emphasis of the model. The natural polarisation of scientist and practitioner is readily apparent in those that teach, students, and even within the body of practitioners as well. Some professionals are not interested in research, and are naturally inclined towards practice (Chang et al., 2008; Maddux \& Riso, 2007).

Third, the role of the supervisor in facilitating this process of exposure to science and integration of science and practice is crucial (Jones \& Mehr, 2007). However, long-term career goals play an important role: academics and thus trainers, focusing on research, lose the crucial input of a practice experience over time. The inclinations of trainers rub off on students and the onus is on trainers to set the example of proper science-practice integration (Overholser, 2007). The converse is also true - trainers focusing on skills training often do not have the time or interest to publish.

However, finally, the most important finding to me was that practitioners view the science model as largely positivist, thus, limited in utility and applicability: '. . . the majority of graduate 
level clinical psychology training programs are based on a flawed version of the scientist-practitioner model that renders the training inadequate and ineffective' (Chang et al., 2008, p. 288). How can you integrate a science model in practice if you are not committed to the paradigm taught to you at university? Despite the lofty ideal of the Boulder and related models, integrating science and practice will never get off the ground if we are stuck in an outmoded scientific paradigm.

Let me briefly illustrate with one of the studies that tried to explain the lack of efficacy of the SP model:

Psychology's current commitment to positivist explanation, scientific knowledge characterized by lawgoverned causal processes, is at the core of the scientist-practitioner split (Chwalisz, 2003, p. 497) . . 'Efforts to establish psychology as a scientific discipline underlie the alignment with a logical positivist philosophy of science ... and its assumption that an objective reality exists that can be observed by researchers. However, psychological phenomena are far too complex . . . to be adequately captured using positivist scientific methods, and psychology has inadvertently limited its knowledge by aligning with positivist science'. (Chwalisz, 2003, p. 499)

Thus, the evidence for EST is regarded as positivist especially where statistics is involved to decide the efficacy of outcomes (Chwalisz, 2003). Some studies call for an expansion of what is viewed as evidence, namely, evidence from single case and qualitative studies and less controlled situations of observation and interpretation. I do not think one needs a redefinition of what counts as evidence; I plead for a revision of what we understand as science, and in the process the myth of positivistic science needs to be laid to rest.

\section{Disentangling the image of science}

The current understanding of the SP model is based on a misunderstanding of what science is (Petocz, 2011, pp. 700-701). We all know that in most, if not all, South African academic institutions training psychologists, we have a deep qualitative-quantitative divide. On some level of understanding, we do grasp the importance of both approaches, to the point that the recent trend is to train post-graduate students in mixed methods (Creswell \& Clark, 2011). We realise that the ideological principles forcing us in one direction or the other cannot forever be upheld; thus, we try to embrace an approach that to some extent either unthinkingly suspends these ideological differences or provides some rationale for using mixed methods.

\section{Methodological differences}

The ideological differences separating quantitative and qualitative approaches should also be briefly pointed out. Our understanding of science involves seeing mainstream psychology as adhering to experimental and empirical methods where quantification plays a major role. This is typically characterised as positivist, and textbook authors and lecturers can be held responsible for perpetuating this view (Neuman, 2012; Terre Blanche, Durrheim, \& Painter, 2006). By being characterised as such, it is a small step to motivating the use of qualitative approaches based on postmodern and constructionist epistemologies and inclinations. The understanding of psychological science as divided into ideographic and nomothetic, that is, working with causal laws (positivist) on the one hand and with meaning (postmodern-constructionist) on the other hand, established the gap fundamentally and resulted in this ideological divide (Lilienfeld, Ritschel, Lynn, Cautin, \& Latzman, 2013). We chastise students for even thinking about sample sizes, validity, and hypotheses when they get involved in qualitative work: their terms, theory, and methods should all speak 
one language and be purified from any positivist residues, and we are getting quite adept at this. It is a matter of principle to immerse yourself as a psychology student in the correct paradigm, namely, a constructionist one. We deal with meaning which cannot be captured by operationalisation and measurement.

Of course, what is known as mainstream psychology internationally is not very concerned with these accusations and psychologists happily continue to do research and theorise about issues ranging from psychometrics, neuropsychology, social psychology, developmental psychology, and cognitive psychology (Mackay \& Petocz, 2011). Some of these trends are reflected in South Africa, but I think we might have a stronger qualitative approach or focus on meaning due to our focus on constructionist, narrative discourse and critical psychology, but still against the backdrop of demonising the remainder as positivist (Michell, 2001). It seems that the qualitative trends internationally are not so prominent and that mainstream still means empirical and quantitative.

However, the focus of our own South African psychological training and methods is understandable given our political development and the requirement to be critical to what was mainstream, namely, White male-dominated positivist science. Crucial work has been done over the last 20 years in psychology in South Africa to correct these views and even expose the biased and discriminatory role institutional psychology played in upholding apartheid-ideology (De la Rey \& Ipser, 2004; Duncan, Stevens, \& Canham, 2014). Given that vital work was done by postmodern and critical psychologists in South Africa, I do think we need to pause once more at what it means to be scientific. The changing context, such as the pressure to train researchers but also meeting current mental health needs in South Africa, requires revising the image we have of science.

\section{Understanding science as critical enquiry}

Let me first deal with the understanding of science, or part of science, as positivistic. Science is not characterised by the ability to quantify; the ability to find causal laws; the ability to operationalise and measure anything that moves; and the ability to be value free, objective, do experimentation, work with things that do not involve meaning, or that can be observed (Michell, 2008). As Petocz (2011) said, 'Genuine science does not presuppose the appropriateness of any individual method (such as measurement), for that must be empirically determined via sensitivity to the nature of the subject matter under investigation' (p. 708). Science is not some sort of entity, set of values, or cognitive framework dictating what we should believe. No, doing science lies solely in critical enquiry. Science does not prescribe the method, neither quantification nor understanding, but merely approaching things in a critical manner. Of course, the difference between natural science and social/human science was always characterised by the nomothetic/ideographic model, but science as a whole is critical and, depending on what we work with, the requirement for measurement and/or hermeneutic understanding comes into play. It is not as if the experimentalist suddenly becomes a clueless rule-following zombie when calculating values for the $5 \%$ exceedance probability. We all impute meaning, construct, interpret, and critically try to understand what is going on with the stuff we work with, which in this case happens to be people or aspects of them.

\section{Science as realist}

Essentially, science is a realist endeavour and it cannot be otherwise. The mere fact that science in whatever guise, social or otherwise, managed to progress despite our preconceived notions shows that scientists work in a realist manner. What does this mean? Realism is the notion that things and events exist independently of the mind (Chakravartty, 2007). Scientific realism is the main philosophical approach in the sciences and there are related versions applied to the social sciences such 
as situational realism and critical realism. Critical realism was assumed to solve many of our scientific conundrums in psychology such as the quantitative-qualitative divide and/or the positivistconstructionist gap (Bhaskar, 1975, 1998). Critical realism explicitly negotiates itself between positivism/empiricism and the constructionist/hermeneutic approach to human behaviour. One of the main tenets of critical realism is reality as consisting of the domains of the empirical, actual, and the real. The bulk of scientific work for positivism is done on the level of the empirical where observation is the primary arbiter of truth. However, the scientist's task is to explore the level of the real where mechanisms operate to produce events and behaviour on the levels of the empirical and the actual (Bhaskar, 1975).

\section{Meaning}

I will call the false image of science, namely, the view that science is positivistic, involves largely quantification, and mixed with a good dose of objectivism, scientistic (Petocz, 2011). One of the main postmodernist complaints against science is its inability to deal with meaning (Lock \& Strong, 2010). I agree that a scientistic view of science has difficulty dealing with meaning. I need to be very clear on this: science is neither scientistic nor positivistic, it is realist and involves critical enquiry. Situational realism (SR) easily incorporates the idea of meaning into science, views meaning as relational and therefore squarely within the domain of psychological science (Petocz, 2011). ${ }^{1}$ One can distinguish between two types of meaning: (a) linguistic/symbolic and (b) experiential. We can distinguish between the two types as follows: (a) a chair or any depiction of a chair means a way to support one's bum to Peter, or briefly, x means y to a and (b) Peter experiences his mother's death as traumatic, or briefly, $\mathrm{x}$ means y to a (Petocz, 2011).

In linguistic or symbolic meaning, a three-way relationship is required, namely, the signifier, the signified, and someone who grasps that the signifier stands for the signified. It is important to realise that meaning is thus not a thing, cannot be reduced to any of the terms of the relationship, and cannot be intrinsic. The fact that we localise meaning within the relationship between the terms cannot relativise meaning; it is this relativisation that 'launches' constructivism and anti-realism (Petocz, 2011, p. 709). We need to realise that $\mathrm{x}$ means $\mathrm{y}$ to $\mathrm{p}$ in a particular context is just as objective and real as any other fact. The three-termed relationship is there and thus within the domain of the investigative psychologist.

The realist acknowledges the cognitive/constructivist nature of critical enquiry: it is fallible, thus, provisional, and cannot claim absolute truth. Realism acknowledges that we work in a reality consisting of relations; thus, some of us enquire about these relations and others focus on the terms. We also know that meaning cannot be measured, but this does not mean the psychologist as scientist cannot scientifically investigate what stuff means to people and why (Petocz, 2011)!

\section{Bridging gaps}

What I am advocating here is a realism where the qualitative-quantitative distinction is irrelevant, where scientists realise that the subject matter determines method and that 'method' means a process assisting critical enquiry. It is also important to realise what the worth and place of measurement is. ${ }^{2}$ Of course, psychology has in its illustrious past mimicked the mythic image of science (Michell, 2000, 2008, 2011). Thus, positivism influenced measurement, experimental methods, and behaviourism, but hopefully we are moving towards a realist model of science and an understanding that quantifying is not a hallmark of science. Let me put it bluntly as someone who was trained in psychometrics and quantitative methods: the onus is on the researcher to show that the constructs he or she is measuring are amenable to measurement (Michell, 2005). Weight is fine, but 
who says that the constructs that we so haphazardly reify such as personality characteristics, mental properties such as IQ, and other cognitive and related phenomena are real? I have conceded one thing: meaning is real but we cannot measure it, so if there are things like non-verbal ability, the question must be whether they can be measured.

So what does realism mean for the psychological scientist and practitioner? Why do we do science with people? Realist science calls for a deep understanding of cause with the realisation that we do not search for absolute and unchanging laws but that we would like to find deep causes or mechanisms to explain why people act as they do (Bhaskar, 1998). We should realise that cause is never or seldom linear. Many things cause things to happen, and if we unravel some of the complexity, we can come to understand people, behaviour, and how and why they can change (Hibberd, 2011).

\section{Some neuropsychological examples of realist psychology}

Neuroscience, despite the hype and over-indulgence, currently affords exciting opportunities to discover and support many psychological phenomena and to explain human behaviour. In fact, the neuronal mechanisms responsible for behaviour and what we call psychological phenomena fall within the ambit of a realist science without negating the psychological level of analysis. What I am saying is that when we find an explanation or mechanism on a lower level or more basic level of explanation such as physiology, it does not immediately imply reductionism in the sense that we can now do away with the psychological level. In fact, most of what we did in psychology over the past years had its basis in physiological events, but because of the lack of knowledge and methods to examine the deeper level, we had to contend with a metaphorical level of dealing with human behaviour and mental processes. My contention is that we will always work with this 'metaphorical' or psychological level because just as chemistry did not dissolve biology, but allows understanding of deeper mechanisms, the neuronal level will enable us to understand what is going on with people, psychologically speaking.

\section{The biological basis of personality}

One of the areas of longstanding debate involves the concept of personality in psychology. Some researchers are staunch believers in the idea of personality consisting of a number of dimensions that adequately explain a person's propensity to act in a certain way in a certain context. On the other hand, constructionist criticism denies the reality of these so-called personality constructs and warns of essentialising and reifying concepts we might think are true of people. Cloninger (1987) developed a psychobiological model of personality. ${ }^{3}$ His research led to the construction of a questionnaire capturing a number of constructs. Four temperament dimensions were identified, namely Harm Avoidance, Novelty Seeking, Reward Dependence, and Persistence. Later three dimensions of character were added, namely, Self-directedness, Cooperativeness, and Self-transcendence (Cloninger, Svrakic, \& Przybeck, 1993). Much research has followed and Cloninger's model has been compared to a number of personality models with different bases (Zuckerman \& Cloninger, 1996). The most popular personality assessment model is the so-called Big Five model based on linguistic descriptions of persons' assessments of themselves. It was found that there is common variance between the different personality theories and models such as Cloninger's and the linguistic-based questionnaires (De Fruyt, Van De Wiele, \& Van Heeringen, 2000). My point is that one might, in a multi-disciplinary way, discover mechanisms underlying so-called personality constructs. Whereas we started off with patterns we could observe in patients, postulating explanations on a psychological level, current neuroscience research might enable us to attach patterns and tendencies of behaviour to simple physiological mechanisms. Something as simple as harm 
avoidance, having a basis in biological structures and behaviour activated by neuro-hormones, can easily develop, in interaction with genetic factors, and social and environmental influences into the complex behaviour of someone we would normally call an introvert (for examples of similar issues, see Puttonen, Ravaja, \& Keltikangas-Järvinen, 2005).

\section{Mirror neurons}

As you probably know, mirror neurons were discovered as recently as 1992 and named mirror neurons in 1996 by a team of researchers working on macaque monkeys (Di Pellegrino, Fadiga, Fogassi, Gallese, \& Rizzolatti, 1992; Gallese, Fadiga, Fogassi, \& Rizzolatti, 1996). The neurons fired in the ventral premotor cortex of the monkeys when looking at movies of movement. Now we know that similar systems exist in the human brain, and they are responsible for empathy, imitating others, predicting the behaviour of others, and the ability to imagine what others are thinking (Rossouw, 2013). In fact, we know now that the mirror neuron system (MNS) is responsible for rather sophisticated predictions of intention.

To reduce a complex account in a few sentences, a mechanism was proposed that originates in the limbic system and escalates to the cortical areas. Two MNS systems can be found: the limbic MNS anterior mesial frontal cortex and the premotor MNS in the parietal lobe and premotor cortex. Intention coding takes place in a hierarchical manner as a bottom-up process. Two aspects are important with intention coding: predicting and minimising prediction error. To use a simple exam-

ple: if this thing in front of me turns out not to be a sheep but a lion, then I have made a heck of a prediction error. Thus, survival depends on making accurate predictions and minimising error. The coding process starts from the limbic system; thus, survival needs are important and travel upwards to the cortical region. It roughly corresponds to Maslow's hierarchy of needs. The MNS is aimed at enhancing survival and minimising error prediction (Rossouw, 2013). Again, there might be a deeper explanation for a psychological model described a number of years ago with only observations of patterns and tendencies of behaviour. In fact, the biological structures can propose a better and more refined model of something like, for instance, the drive and need psychological structure. Thus, discovering and searching for underlying causal mechanisms for patterns of behaviour lies within the ambit of a realist endeavour of a scientific psychology.

\section{Conclusion}

In conclusion, we need to base the SP roles on realist principles which in effect means that we need to revise our understanding of what both concepts mean. Most importantly, we need to clarify our understanding of science. Avoiding scientistic images of what it means to be scientific is crucial for a proper integration of the SP model. We also, as realists, need to locate the primary scientific orientation in critical inquiry - at least this is what we have in common with our fellow constructionist scientists. Overcoming dualisms or polarities such as quantitative-qualitative, nomographic-ideographic, and even scientist-practitioner is possible within a realist approach.

\section{Author note}

Different versions of this article were presented at the 7th World Congress for Psychotherapy, 25-29 August, Durban, South Africa and as an Inaugural Address, 30 October 2014, University of Pretoria.

\section{Funding}

This research received no specific grant from any funding agency in the public, commercial, or not-for-profit sectors. 


\section{Notes}

1. The resulting tensions - ranging from uneasy alliance to radical schism - between 'science' on the one hand and 'meaning' on the other are reflected in practice in the clashes between putatively scientific and evidence-based treatments, usually behavioural or cognitive-behavioural, and enshrined in the SP model, and the more humanistic and psychodynamically-oriented approaches, which employ interpretative techniques to address the 'subjective meanings' and 'lived experiences' held to be central in the psychotherapeutic or psychoanalytic encounter. (Petocz, 2011, pp. 700-701)

2. '.. the practice of measurement is continuous with scientific investigation generally: it is the attempt to find out something' (Michell, 2005, p. 287).

3. Temperament was conceptualised as corresponding to heritable biases in memory processing involved in pre-semantic perceptual processing and encoding of concrete visuospatial structural information and affective valence. These processes were hypothesised to be functionally organised as independently varying brain systems aligned to specific monoaminergic cell bodies which in turn are responsible for autonomic responses involved in the activation, maintenance and inhibition of behaviour. (Gillespie, Cloninger, Heath, \& Martin, 2003, p. 1932)

\section{References}

Bhaskar, R. (1975). A realist theory of science. London, England: Verso.

Bhaskar, R. (1998). The possibility of naturalism: A philosophical critique of the contemporary human sciences (3rd ed.). London, England: Routledge.

Chakravartty, A. (2007). A metaphysics for scientific realism: Knowing the unobservable. Cambridge, UK: Cambridge University Press.

Chang, K., Lee, I.-L., \& Hargreaves, T. A. (2008). Scientist versus Practitioner - An abridged metaanalysis of the changing role of psychologists. Counselling Psychology Quarterly, 21, 267-291. doi:10.1080/09515070802479859

Chwalisz, K. (2003). Evidence-based practice: A framework for twenty-first-century scientist-practitioner training. The Counseling Psychologist, 31, 497-528. doi:10.1177/0011000003256347

Clegg, S. (2007). Evidence-based practice in educational research: A critical realist critique of systematic review. British Journal of Sociology of Education, 26, 415-428. doi:10.1080/01425690500128932

Cloninger, C. R. (1987). A systematic method for clinical description and classification of personality variants: A proposal. Archives of General Psychiatry, 44, 573-588.

Cloninger, C. R., Svrakic, D. M., \& Przybeck, T. R. (1993). A psychobiological model of temperament and character. Archives of General Psychiatry, 50, 975-990.

Creswell, J. W., \& Clark, V. L. P. (2011). Designing and conducting mixed methods research (2nd ed.). Thousand Oaks, CA: SAGE.

De Fruyt, F., Van De Wiele, L., \& Van Heeringen, C. (2000). Cloninger's psychobiological model of temperament and character and the five-factor model of personality. Personality and Individual Differences, 29, 441-452.

De la Rey, C., \& Ipser, J. (2004). The call for relevance: South African psychology ten years into democracy. South African Journal of Psychology, 34, 544-552.

Di Pellegrino, G., Fadiga, L., Fogassi, L., Gallese, V., \& Rizzolatti, G. (1992). Understanding motor events: A neurophysiological study. Experimental Brain Research, 91, 176-180.

Duncan, N., Stevens, G., \& Canham, H. (2014). Living through the legacy: The Apartheid Archive Project and the possibilities for psychosocial transformation. South African Journal of Psychology, $44,282-291$.

Floersch, J. (2004). A method for investigating practitioner use of theory in practice. Qualitative Social Work, 3, 161-177. doi:10.1177/1473325004043381

Gallese, V., Fadiga, L., Fogassi, L., \& Rizzolatti, G. (1996). Action recognition in the premotor cortex. Brain, $119,593-609$.

Gelso, C. J. (2006). On the making of a scientist-practitioner: A theory of research training in professional psychology. Training and Education in Professional Psychology, 5, 3-16. 
Gillespie, N. A., Cloninger, C. R., Heath, A. C., \& Martin, N. G. (2003). The genetic and environmental relationship between Cloninger's dimensions of temperament and character. Personality and Individual Differences, 35, 1931-1946. doi:10.1016/S0191-8869(03)00042-4

Hibberd, F. J. (2011). Anderson's development of (situational) realism and its bearing on psychology today. In N. Mackay \& A. Petocz (Eds.), Realism and psychology: Collected essays (pp. 119-158). Boston, MA: Brill.

Horn, R. A., Troyer, J. A., Hall, E. J., Mellott, R. N., Coté, L. S., \& Marquis, J. D. (2007). The scientistpractitioner model: A rose by any other name is still a rose. American Behavioral Scientist, 50, 808-819.

Jones, J. L., \& Mehr, S. L. (2007). Foundations and assumptions of the scientist-practitioner model. American Behavioral Scientist, 50, 766-771. doi:10.1177/0002764206296454

Lilienfeld, S. O., Ritschel, L. A., Lynn, S. J., Brown, A. P., Cautin, R. L., \& Latzman, R. D. (2013). The research-practice gap: Bridging the schism between eating disorder researchers and practitioners. International Journal of Eating Disorders, 46, 386-394. doi:10.1002/eat.22090

Lilienfeld, S. O., Ritschel, L. A., Lynn, S. J., Cautin, R. L., \& Latzman, R. D. (2013). Why many clinical psychologists are resistant to evidence-based practice: Root causes and constructive remedies. Clinical Psychological Review, 33, 883-900. doi:10.1016/j.cpr.2012.09.008

Lock, A., \& Strong, T. (2010). Social constructionism: Sources and stirrings in theory and practice. Cambridge, UK: Cambridge University Press.

Lowman, R. L. (2012). The scientist-practitioner consulting psychologist. Consulting Psychology Journal: Practice and Research, 64, 151-156. doi:10.1037/a0030365

Lund, C., Kleintjes, S., Kakuma, R., \& Flisher, A. J. (2010). Public sector mental health systems in South Africa: Inter-provincial comparisons and policy implications. Social Psychiatry Epidemiology, 45, 393404. doi:10.1007/s00127-009-0078-5

Lund, C., Petersen, I., Kleintjes, S., \& Bhana, A. (2012). Mental health services in South Africa: Taking stock. African Journal of Psychiatry, 15, 402-405. Retrieved from http://dx.doi.org/10.4314/ajpsy.v15i6.48

Mackay, N., \& Petocz, A. (2011). Realism and the state of theory in psychology. In N. Mackay \& A. Petocz (Eds.), Realism and psychology: Collected essays (pp. 17-51). Boston, MA: Brill.

Maddux, R. E., \& Riso, L. P. (2007). Promoting the scientist-practitioner mindset in clinical training. Journal of Contemporary Psychotherapy, 37, 213-220. doi:10.1007/s10879-007-9056-y

Mellott, R. N. (2007). Introduction: The scientist-practitioner training model for professional psychology. American Behavioral Scientist, 50, 755-757.

Michell, J. (2000). Normal science, pathological science and psychometrics. Theory \& Psychology, 10, 639667. doi:10.1177/0959354300105004

Michell, J. (2001). Teaching and misteaching measurement in psychology. Australian Psychologist, 36, $211-$ 218.

Michell, J. (2005). The logic of measurement: A realist overview. Measurement, 38, 285-294.

Michell, J. (2008). Is psychometrics pathological science? Measurement, 6, 7-24. doi:10.1080/ 15366360802035489

Michell, J. (2011). Normal science, pathological science and psychometrics. In N. Mackay \& A. Petocz (Eds.), Realism and psychology: Collected essays (pp. 461-499). Boston, MA: Brill.

Neuman, W. L. (2012). Basics of social research: Qualitative and quantitative approaches (3rd ed.). Boston, MA: Pearson.

Overholser, J. C. (2007). The Boulder model in academia: Struggling to integrate the science and practice of psychology. Journal of Contemporary Psychotherapy, 37, 205-211. doi:10.1007/s10879-007-9055-z

Petocz, A. (2011). Science, meaning and the scientist-practitioner model of treatment. In N. Mackay \& A. Petocz (Eds.), Realism and psychology: Collected essays (pp. 699-726). Boston, MA: Brill.

Puttonen, S., Ravaja, N., \& Keltikangas-Järvinen, L. (2005). Cloninger's temperament dimensions and affective responses to different challenges. Comprehensive Psychiatry, 46, 128-134. doi:10.1016/j. comppsych.2004.07.023

Ramlall, S. (2012). The Mental Health Care Act No 17-South Africa. Trials and triumphs: 2002-2012. African Journal of Psychiatry, 15, 407-410. Retrieved from http://dx.doi.org/10.4314/ajpsy.v15i6.49

Ramokgopa, G. (2012). A milestone for mental health in South Africa. African Journal of Psychiatry, 15, 379. Retrieved from http://dx.doi.org/10.4314/ajpsy.v15i6.46 
Rice, C. E. (1997). The scientist practitioner split and the future of psychology. American Psychologist, 52, $1173-1181$.

Rossouw, P. J. (2013). The neuroscience of talking therapies: Implications for therapeutic practice. The Australian Journal of Counselling Psychology, 13, 40-48.

Sauer, E. M. (2006). Living the scientist-practitioner model in a psychology training clinic. Counselling Psychology Quarterly, 19, 293-304. doi:10.1080/09515070600960498

Stoltenberg, C. D., \& Pace, T. M. (2007). The scientist-practitioner model: Now more than ever. Journal of Contemporary Psychotherapy, 37, 195-203. doi:10.1007/s10879-007-9054-0

Stoltenberg, C. D., Pace, T. M., Kashubeck-West, S., Biever, J. L., Patterson, T., \& Welch, I. D. (2000). Training models in counseling psychology: Scientist-practitioner versus practitioner-scholar. The Counseling Psychologist, 28, 622-640. doi:10.1177/0011000000285002

Tanner, P. L., \& Danielson, M. L. (2007). Components necessary for the preparation of the scientistpractitioner. American Behavioral Scientist, 50, 772-777.

Terre Blanche, M. J., Durrheim, K., \& Painter, D. (2006). Research in practice: Applied methods for the social sciences (2nd ed.). Cape Town, South Africa: UCT Press.

Vespia,K.M., Sauer,E. M., \& Lyddon, W.J.(2006). Counselling psychologists as scientist-practitioners: Finding unity in diversity. Counselling Psychology Quarterly, 19, 223-227. doi:10.1080/09515070600960506

Zuckerman, M., \& Cloninger, C. R. (1996). Relationships between Cloninger's, Zuckerman's, and Eysenck's dimensions of personality. Personality and Individual Differences, 21, 283-285. 